\title{
Developing a Review Rubric for Learning Resources in Digital Libraries
}

Heather Leary, Utah State University

Sarah Giersch, Columbia University

Andrew Walker, Utah State University

Mimi Recker, Utah State University

\begin{abstract}
This paper describes the development of a review rubric for learning resources in the context of the Instructional Architect (IA), a web-based authoring tool. We describe the motivation for developing a review rubric, the process for creating it by synthesizing the rubrics of other education-related digital libraries, and the results of testing the rubric with teachers. Analysis of usability and reliability indicates that the review rubric influences how teachers design online learning resources.
\end{abstract}

\section{Keywords}

Education Digital Library, Review Rubric, Instructional Architect, National Science Digital Library.

\section{Introduction}

The Internet has democratized content creation and dissemination by individuals (Anderson, 2006), activities that were previously controlled by editors, publishers, advertisers and retailers. While web-based services, online tools and peer-to-peer community structures, which support creating, using and disseminating online content, have flourished in the commercial and personal-use sectors, within K12 and higher education in the United States, use of online content in the classroom is not ubiquitous, and educators are not consistently creating and disseminating their own content online.

Over the past 10-15 years, educational digital libraries have become the repositories for online learning resources of varying levels of granularity and of varying sources of authorship. Coupled with increased classroom access to the Internet, digital libraries enable much greater use of online resources by teachers and learners, though as noted, use is not consistent. Funding agencies like the National Science Foundation (http://nsf.org) have begun supporting initiatives to develop a social and technical cyber-infrastructure, which encompasses digital libraries and which seeks to integrate teachers and learners into the education cyber-infrastructure to become co-creators of educational content (Computing Research Association, 2005).

While such initiatives encourage and expand educators' capacity and opportunities to create online educational content, there are calls to ensure that the content promotes learning in formal and informal settings. In the past, when digital libraries collected learning resources, they depended on the reputation and oversight of a funding organization, the credentials of the content creator, or the collection development policies of specific digital libraries to establish an imprimatur for online resource quality. However, the very factors that ensure the wide availability of online learning resources (easy-to-use tools for individual creation and dissemination) also place them outside the commonly accepted review processes, such as those maintained by journals or professional societies. The challenge for digital libraries is to balance collecting and providing access to online learning resources while maintaining a level of resource quality that distinguishes digital libraries from vanilla Internet search engines. Resources created by teachers and learners, often for niche concepts or user groups, may not be part of established review processes, but have the potential to impact learning (Hanson \& Carlson, 2005). 
Many digital library builders have established review rubrics to evaluate the quality online educational resources generated by users (e.g., teachers and faculty) (Fitzgerald, Lovin, \& Branch, 2003; Lamantia, 2003; Maurer, \& Warfel, 2004), though their motivations differ. Some libraries have developed rubrics to identify high quality online resources in order to establish their reputation with users (Robertshaw, Leary, Walker, Bloxham, Recker, 2009). And, some use rubrics to determine the inclusion of high quality resources in a digital library or repository (Lamantia, 2003; Maurer, \& Warfel, 2004) because use of a collection development policy for inclusion of quality resources adds value and buy-in from peer reviewers and users (Robertshaw et al., 2009). In addition to establishing a reputation and informing collection development decisions, one site also developed a rubric to guide authors in creating high quality online resources (McMartin, 2004) by gathering feedback from target users. Another

(Recker, Walker, Giersch, Mao, Halioris, Palmer, Johnson, Leary, Robertshaw, 2007) developed a rubric as the basis for a service, which gathered data through automated suggestions and from previous online resource selections, to provide teachers with recommendations on other, similar resources to use.

Although many review rubrics have already been created, they are specific to each digital library with little room for re-use outside of their original context. As such, our goal was to synthesize the various dimensions of existing DL rubrics in order to identify a standardized set of criteria that could potentially be used by any digital library with online educational resources and to create a review rubric for the Instructional Architect projects.

The project objectives were to develop a rubric based on prior literature, evaluate its utility and usability with users (teachers), test its reliability, explore its impact in fostering teacher skills in designing learning resources, and to identify quality projects for inclusion in educational digital libraries, such as the NSDL. This work is conducted within the context of the Instructional Architect, a simple, web-based authoring service that supports K12 teachers in finding and assembling online content into lessons for their classroom (Robertshaw et al., 2009). This paper reviews the process for generating the rubric, and reports findings from formative and summative evaluations. In particular, it describes findings from an exploratory study in which U.S. K-12 teachers used the rubric to evaluate their own and others' resources.

\section{The Instructional Architect}

The Instructional Architect (IA) is an Internet based authoring tool designed to help K12 teachers find, design, and use online learning resources in their classrooms. As a result of using the IA, teachers create 'IA projects' (in the form of web pages) that contain instructional objectives, activities, and assessments with links to digital library and online resources. In this way, teachers create IA projects that customize resources to their local context.

IA users have now created an abundance of projects in need of evaluation before they can be included in digital libraries like the National Science Digital Library. To support this, the review process and rubric must be reliable, useful, as well as scalable.

\section{Creating the Review Rubric}

The process for developing the review rubric began with a literature review in the disciplines of computer science, library and information science, education (specifically online learning objects), and digital libraries. We selected only articles that included or referenced rubrics used to review online educational resources with the intention of using the rubrics' criteria as a foundation for our review rubric. The review yielded articles with 12 rubrics. 
To synthesize and analyze the rubrics, we used a card sort technique, which is a user-centered design method developed by information architects for assessing web site structure (Liu, \& Ward, 2007). In particular, we distilled 104 review criteria from the rubrics using the following parameters: criteria must include a definition and must make sense when read outside the context of its original rubric. A detailed description of the subsequent analysis (Giersch, Leary, Palmer, Recker, 2008a; Giersch, Leary, Palmer, Recker, 2008b) resulted in the initial review rubric (Figure 1). In the draft rubric, the statements in bold correspond to the group names developed by study participants in the card sort exercise (e.g., Content). The items (e.g., accurate) are criteria from the original 12 rubrics that participants associated with the group names. The numbers in brackets note the original rubrics and correspond to articles in the references section below, except for criteria provided by an external Review Committee that is part of the project.

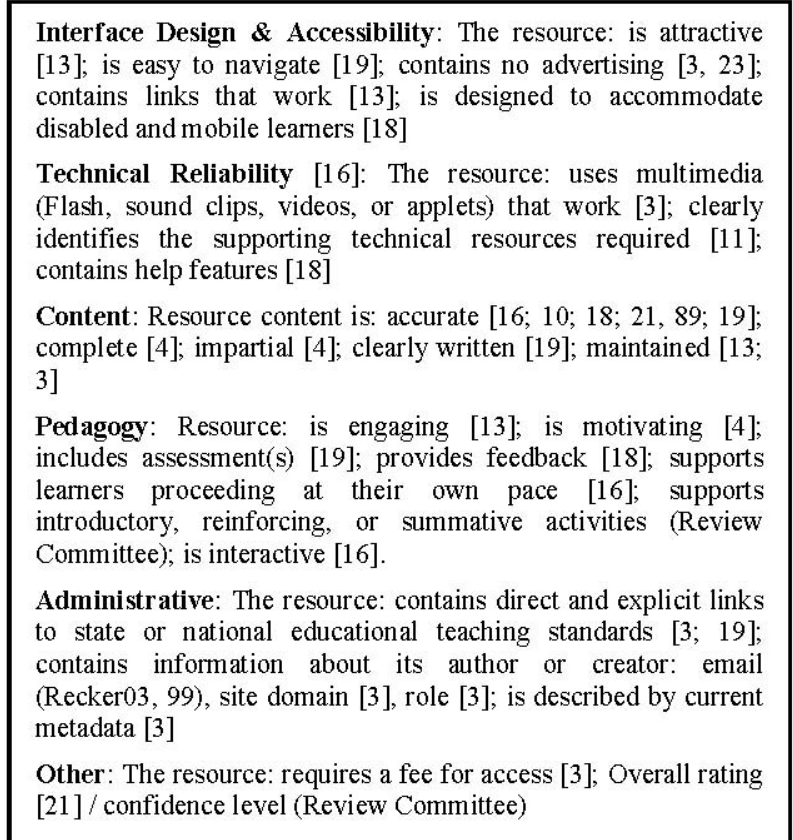

Figure 1. IA Review Rubric: Criteria and Definitions (Draft, August 2008)

\section{Evaluation}

After creating the initial review rubric, we further modified it and conducted formative evaluations of the rubric by testing and refining it with 25 participants, including researchers, school library media specialists, and other experts in education In Fall 2008, we conducted a summative evaluation of the rubric, described next. Our objectives were to gather feedback to make improvements to the rubric, assess its reliability, and explore how using it affected participants' skills as they created online educational resources. Our specific research questions were:

What were participants' reactions to the rubric?

Was the rubric helpful in improving the quality of participants' own IA projects?

Did participants find reviews of their IA projects useful?

Did study data inform rubric refinements?

Was the rubric reliable?

\section{Methods}

Participants 
Participants ( $\mathrm{N}=28$ ) were part of a cohort of U.S. K-12 teachers in an online graduate program, and who completed required activities as part of an online course. Complete data were received from 17 participants.

\section{Data Sources}

The participants took part in an online learning module in the context of learning how to use the IA and the review rubric. They completed pre-and post-online surveys, which used a combination of open-ended and lickert scale questions. Surveys measured the extent of participants' experience and classroom practice in using online educational resources; their attitudes about online educational resources and technology general and their use in a classroom; and, strategies for evaluating an online educational resource. Within the learning module, participants were placed in small groups of 4-5 participants where they evaluated one another's IA projects using the review rubric. Conversations about these evaluations were posted in a BlackBoard discussion forum and collected by researchers. Lastly, participants' wrote a reflection paper describing their experience using the IA, how they used online educational resources in an instructional situation, difficulties and successes in designing and implementing their project, what they learned by reviewing their peers' IA projects and by using the review rubric, and how they could improve their IA project.

\section{Findings}

Data were analyzed using a mixed methods approach. From the pre-and post-survey lickert items, means, standard deviations and effect sizes were calculated on questions relating to participants' attitude, experience with and use of online educational resources and technology in their classrooms in order to understand changes in participants' pedagogical choices and activities in their classrooms. Small, but positive changes were shown as teachers reported that they knew how to effectively teach with technology in the classroom $(\mathrm{dw}=0.28, \mathrm{p}<0.05)$, and they knew how to effectively use technology in their classroom $(\mathrm{dw}=0.42, \mathrm{p}<0.05)$. We can infer that after participating in the learning module, teachers had begun to overcome the initial barriers of using technology in the classroom and could now focus on making better pedagogical decisions about the type of learning resources they could create. We then used a qualitative analysis to address the research questions above, with the understanding that participants had learned how to use online educational resources.

Using a constant comparative analysis (Glaser \& Strauss, 1967), data from the reflection papers, discussion boards, and one question in the pre-and post-survey were mapped into themes and analyzed. Participants reported in the pre-survey that when evaluating online educational resources they looked for "fit with the curriculum," accuracy, ease of use, currency, text readability, and recommendations by others. After completing this course module, participants added in their post-survey: content quality, distractions on the resource pages, credibility of the site, and "will it engage participants.” Many of the criteria they added were items listed in the review rubric. Thus, it appeared that use of the rubric help refine participants' approach to designing learning resources.

Throughout the discussion boards the participants posted their evaluations of their peers' IA projects. Some participants commented on the readability and text clarity of the project, and many caught spelling errors. One participant commented after receiving some feedback, "I have learned that having a peer read through my projects can be very valuable. They catch mistakes that I do not see.” Overall, 53\% of the participants reported that providing and receiving feedback from their peers via reviews was valuable. 
Two additional themes surfaced on the discussion boards during the process of peer evaluation that related to re-use of other teachers' IA projects and ideas. First, participants asked if they could use an IA project they reviewed, or said they were going to use it in their classroom. Often participants said, "Can I use it in [my] class?” The second theme was that participants learned what others had done and wanted to implement the same idea in their project. A participant commented that, "Completing a peer review gives us an opportunity to see other creations and improve our programs as we see fit."

The final data collection point included self-report reflection papers. Participants were asked to report on their instructional situation, successes and difficulties, what they learned from their peers and using the review rubric, and how they could improve their project. Three areas of learning were repeatedly reported in the reflection papers: what they learned by reviewing peer work; what they learned for their own work; and, the value of re-using projects. Similar ideas were also expressed throughout the discussion boards and survey answers.

\section{Reliability and Improvements}

The draft rubric in Figure 1 was modified for use in the Fall 2008 class, and it was this version (see Figure 2) of the rubric that we tested for reliability in order to understand its usefulness and to identify improvements for future use. We used the scores that participants in the Fall 2008 course gave one another's projects. Rubric criteria are scored on a scale of $0-4$, where 0 is low (e.g., very unclear) and 4 is high (e.g., very clear). Questions 1-4 and 6 were analyzed using an intra-class correlation (scale of -1 to 1 , high agreement is found as it approaches 1, with less agreement as it approaches zero). For question 1, participant's ratings of peer projects were in perfect agreement, while questions 2-4 and 6 ranged from -0.3 to 0.06 . This range in scores can be attributed to two characteristics of the participants: they have a close working relationship with the peers they were rating; and, educators as a group tend provide higher ratings. Very few of the participants’ scores deviated from these higher ratings, and when they did, the scores had little agreement. 
Figure 2. IA Review Rubric: Tested in Fall 2008 course.

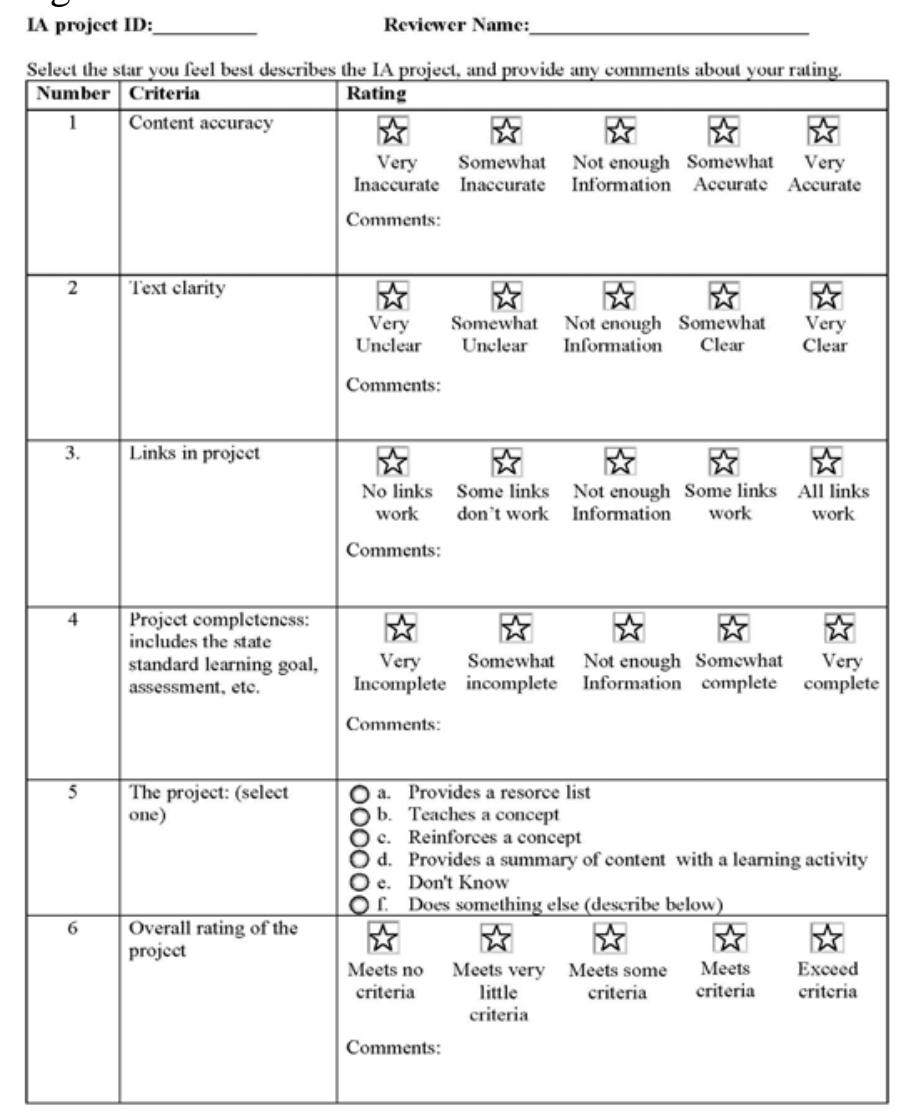

The reliability analysis, suggests that the rubric scale needs more explanation and needs to encompass a broader range. Other improvements made as a result of testing include adding more detailed definitions of the review criteria, re-arranging the order of criteria, and modifying scoring instructions. The most current version can be found at http://digitalcommons.usu.edu/itls_research/5/.

\section{Conclusions}

The results of our evaluation indicate that participants found value in the review rubric as a means to improve the quality of their projects through completing and receiving reviews. Additionally, the first draft of the review rubric, which can be used by any digital library developer to evaluate the quality of online learning resources, can also be modified, as in the case of IA, to create a review rubric that changes a teachers perspective and behaviors around designing online educational resources.

Future work will include creating a workflow for using an external review committee to evaluate projects for inclusion into the National Science Digital Library; integrating reviewing within the IA tool; additional testing to improve rubric reliability and applicability to a range of online educational resources; and, further testing the initial rubric with other digital libraries

\section{Acknowledgements}

The authors would like to thank the study participants for their prompt feedback and assistance. This work was funded by a grant from the National Science Foundation (ESI\# 0554440). 


\section{References}

Anderson, C. (2006). The Long Tail: Why the future of business is selling less of more. Hyperion, New York, New York.

Computing Research Association. (2005). Cyber-infrastructure for Education and Learning for the Future: A vision and research agenda. Washington, D.C.

Custard, M., \& Sumner, T. (2005). Using Machine Learning to Support Quality Judgments. D-Lib Magazine, 11(11).

Fitzgerald, M.A., Lovin, V., \& Branch, R.M. (2003). A Gateway to Educational Materials: An Evaluation of an Online Resource for Teachers and an Exploration of User Behaviors. Journal of Technology and Teacher Education, 11(1), 21-51.

Glaser, B. G. and A. L. Strauss (1967). The discovery of grounded theory: Strategies for qualitative research. Chicago, Aldine Publishing Company.

Giersch, S., Leary, H., Palmer, B., Recker, M. (2008)a. Supporting Meaningful Learning with Online Resources: Developing a Review Process. In Proceedings of the Annual Open Education Conference, Logan, Utah, September 24-26.

Giersch, S. Leary, H., Palmer, B., \& M., Recker (2008)b. Developing a Review Process for Online Resources. In Proceedings of the Joint Conference on Digital Libraries, Pittsburgh, PA, June 15-20.

Hanson, K. \& Carlson, B. (2005). Effective Access Report. Education Development Center.

Kastens, K., DeFelice, B., Devaul, H., DiLeonardo, C., Ginger, K., Larsen, S., et al. (2005). Questions \& Challenges Arising in Building the Collection of a Digital Library for Education: Lessons from Five Years of DLESE. D-Lib Magazine, 11(11).

Knox, D., et al (1999). The Peer Review Process of Teaching Materials: Report of the ITiCSE'99 Working Group on Validation of the quality of teaching materials. Annual Joint Conference Integrating Technology into Computer Science Education, Cracow, Poland.

Lamantia, J. (2003). Analyzing Card Sort Results with a Spreadsheet Template. Retrieved January 18, 2008, from Boxes and Arrows Web site: http://www.boxesandarrows.com/view/analyzing_card_sort_ results_with_a_spreadsheet_template.

Liu, K. \& Ward, V. (2007). Access Excellence @ the National Health Museum. D-Lib Magazine, 13(11/12).

Maurer, D. \& Warfel, T. (2004). Card Sorting: a definitive guide. Retrieved January 18, 2008, from Boxes and Arrows Web site: http://www.boxesandarrows.com/view/card_sorting_a_defini tive_guide

McMartin, F. (2004). MERLOT: A Model for User Involvement in Digital Library Design and Implementation. Journal of Digital Information, 5(3). 
Muramatsu, B. \& Agogino, A. (1999). The National Engineering Education Delivery System: A Digital Library for Engineering Education. D-Lib Magazine, 4(5).

Nesbit, J., Belfer, K., Leacock, T. (2003). Learning Object Review Instrument (LORI 1.5), User Manual. Retrieved January 15, 2008.

Recker, M., Walker, A., Giersch, S., Mao, X., Halioris, S., Palmer, B., Johnson, D., Leary, H., Robertshaw, M.B. (2007). A study of teachers' use of online learning resources to design classroom activities. New Review of Hypermedia and Multimedia, 13(2), 117-134.

Recker, M., Walker, A,. \& Lawless, K. (2003). What do you recommend? Implementation and analyses of collaborative information filtering of web resources for education. Instructional Science, 31, 299-316.

Robertshaw, M. B., Leary, H., Walker, A., Bloxham, K., Recker, M. (2009). Reciprocal mentoring “in the wild”: A retrospective, comparative case study of ICT teacher professional development. In E. Stacey (Ed.) Effective Blended Learning Practices: Evidence-Based Perspectives in ICT-Facilitated Education, Melbourne: IGI Global Press.

Sumner, T., Khoo, M., Recker, M., \& Marlino, M. (2003). Understanding educator perceptions of "quality" in digital libraries. In Proceedings of the Joint Conference on Digital Libraries, Houston, Texas, May 27-31. 